\title{
Frequency and follow-up of cytological studies diagnosed as atypical squamous cell (ASC) at Instituto Nacional de Cancerologia from 2000 to 2004
}

\author{
María Verónica Arce-Grijalva*, Rita Sotelo-Regil Hallmann, \\ Margarita Ibarra del Río and Carlos Enrique González Carrillo
}

Address: Department of Cytopathology, Instituto Nacional de Cancerología, México

Email: María Verónica Arce-Grijalva* - mave441@yahoo.com.mx

* Corresponding author

from 24 $4^{\text {th }}$ Annual Meeting of the National Cancer Institute of Mexico

Mexico City, Mexico. 14-17 February 2007

Published: 5 February 2007

BMC Cancer 2007, 7(SuppI I):A22 doi:I0.1 I86/I47I-2407-7-SI-A22

This article is available from: http://www.biomedcentral.com/I47I-2407/7/SI/A22

(C) 2007 Arce-Grijalva et al; licensee BioMed Central Ltd.

\section{Background}

ASC is the most frequent abnormal diagnosis in the interpretation of cervicovaginal cytology (CVC), it represents from 1 to $9 \%$. There is not much known about its frequency or proportion in groups of high risk, such as the ones that are seen at Instituto Nacional de Cancerologia, center of reference for cancer treatment.

\section{Materials and methods}

A total of 64,602 CVC were retrieved from files at the Cytopathology Department of the Instituto Nacional de Cancerologia, conventional Papanicolaou slides were reviewed, and all cases from patients without previous cytologic, histologic or surgical diagnosis of epithelial abnormalities were included. Data related with age, gynecoobstetric background, type and time of observations were obtained from clinical files.

\section{Results}

565 ASC cases from patients without previous cytologic, histologic or surgical diagnosis of epithelial abnormalities were identified during a period of five years (2000 to 2004). They constituted $6.6 \%$ of abnormal diagnosis, with an ASC: Squamous intraepithelial lesion (SIL) relation of $0.06: 1 ; 316$ cases were excluded, and 229 patients were the study group. $69 \%$ were premenopausic, $42.4 \%$ of them were observed and followed by cytology, colposcopy and biopsy. Coppleson I (31.9\%) was the main colposcopic diagnosis, whereas in $51.4 \%$ an inflammatory cytologic diagnosis was done, and in $41.9 \%$ a low grade squamous intraepithelial lesion was the histological diagnosis.

\section{Conclusion}

The combination of cytology, colposcopy and biopsy is recommendable for detection of cervical abnormalities, as well as the correlation of the three methods permits to avoid aggressive and unnecessary invasive procedures. 